\title{
In-vivo assessment of osseous versus non-osseous transmission pathways of vibratory stimuli applied to the bone and the dura in humans
}

\author{
Stump, Reto ; Dobrev, Ivo ; Krayenbühl, Niklaus ; Probst, Rudolf ; Röösli, Christof
}

\begin{abstract}
Background Bone conduction (BC) is an alternative to air conduction (AC) for stimulation of the inner ear. Stimulation for BC can occur directly on the skull bone, on the skin covering the skull bone, or on soft tissue (i.e., eye, dura). All of these stimuli can elicit otoacoustic emissions (OAE). This study aims to compare OAEs generated by different combinations of stimuli in live humans, including direct stimulation of the intracranial contents via the dura, measured intraoperatively. Methods Measurements were performed in five normal-hearing ears of subjects undergoing a neurosurgical intervention with craniotomy in general anesthesia. Distortion product OAEs (DPOAEs) were measured for f2 at 0.7, $1,2,3,4$, and $6 \mathrm{kHz}$ with a constant ratio of the primary frequencies (f2/f1) of 1.22 . Sound pressure L1 was held constant at $65 \mathrm{~dB}$ SPL, while L2 was decreased in $10 \mathrm{~dB}$ steps from 70 to $30 \mathrm{~dB}$ SPL. A DPOAE was considered significant when its level was $6 \mathrm{~dB}$ above the noise floor. Emissions were generated sequentially with different modes of stimulation: 1) pre-operatively in the awake subject by two air-conducted tones (AC-AC); 2) within the same session preoperatively by one air- and one boneconducted tone on the skin-covered temporal bone as in audiometry (AC-BC); 3) intra-operatively by one air-conducted tone and one bone-vibrator tone applied directly on the dura (AC-DC). A modified bone vibrator (Bonebridge; MED-EL, Innsbruck, Austria) was used for BC stimulation on the dura or skin-covered mastoid. Its equivalent perceived SPL was calibrated preoperatively for each individual by psychoacoustically comparing the level of a $\mathrm{BC}$ tone presented to the temporal region to an $\mathrm{AC}$ tone at the same frequency. Simultaneously with the DPOAEs, vibrations at the teeth were measured with an accelerometer attached using a custom-made holder. Results It was possible to record DPOAEs for all three stimulation modes. For AC-DC, DPOAEs were not detected above the noise floor below $2 \mathrm{kHz}$ but were detectable at the higher frequencies. The best response was measured at or above $2 \mathrm{kHz}$ with $\mathrm{L} 2=60 \mathrm{~dB}$ SPL. The acceleration measured at the teeth for stimulation on the dura was lower than that for stimulation on the bone, especially below $3 \mathrm{kHz}$. Conclusion We demonstrate a proof-of-concept comparison of DPOAEs and teeth acceleration levels elicited by a bone vibrator placed either against the skin-covered temporal bone, as in audiometry, or directly against the dura mater in patients undergoing a craniotomy. It was demonstrated that DPOAEs could be elicited via non-osseous pathways within the skull contents and that the required measurements could be performed intra-operatively.
\end{abstract}

DOI: https://doi.org/10.1016/j.heares.2018.09.007

Posted at the Zurich Open Repository and Archive, University of Zurich ZORA URL: https://doi.org/10.5167/uzh-156973

Journal Article Accepted Version 
The following work is licensed under a Creative Commons: Attribution-NonCommercial-NoDerivatives 4.0 International (CC BY-NC-ND 4.0) License.

Originally published at:

Stump, Reto; Dobrev, Ivo; Krayenbühl, Niklaus; Probst, Rudolf; Röösli, Christof (2018). In-vivo assessment of osseous versus non-osseous transmission pathways of vibratory stimuli applied to the bone and the dura in humans. Hearing Research, 370:40-52.

DOI: https://doi.org/10.1016/j.heares.2018.09.007 


\section{In-vivo assessment of osseous versus non-osseous transmission pathways of vibratory stimuli applied to the bone and the dura in humans}

Reto Stumpa, b

Ivo Dobreva, b

Niklaus Krayenbühl ${ }^{\mathrm{b}, \mathrm{c}}$

Rudolf Probst $^{\mathrm{a}, \mathrm{b}}$

Christof Rööslij ${ }^{\mathrm{a}}$, , *

christof.roeoesli@usz.ch

aDepartment of Otorhinolaryngology, Head and Neck Surgery, University Hospital Zürich, Zürich, Switzerland

bUniversity of Zürich, Zürich, Switzerland

${ }^{\mathbf{c}}$ Department of Neurosurgery, University Hospital Zürich, Zürich, Switzerland

${ }^{*}$ Corresponding author. Department of Otolaryngology, Head and Neck Surgery, University Hospital Zürich, Frauenklinikstrasse, 24 8091, Zürich, Switzerland.

\section{Abstract}

Background

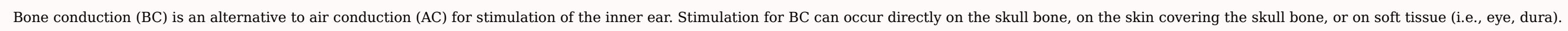

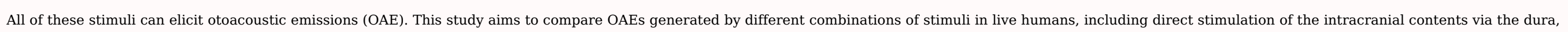
measured intraoperatively.

\section{Methods}

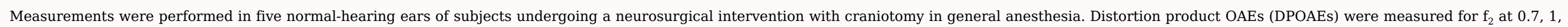

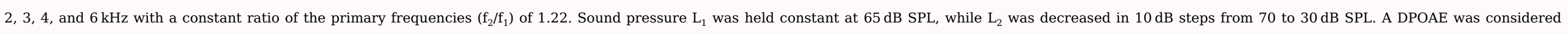

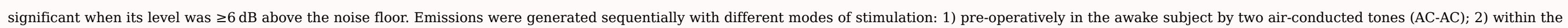

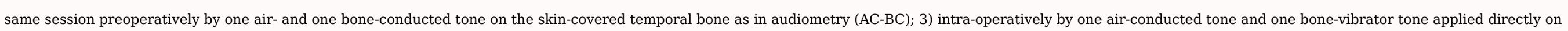

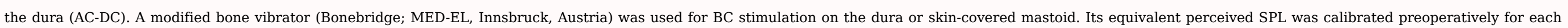

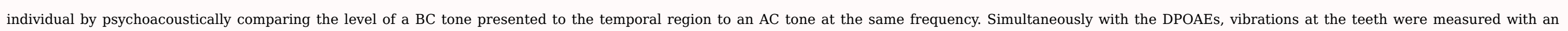
accelerometer attached using a custom-made holder.

Results

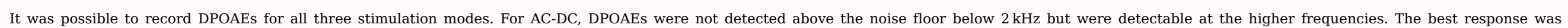
measured at or above $2 \mathrm{kHz}$ with $\mathrm{L}_{2}=60 \mathrm{~dB}$ SPL. The acceleration measured at the teeth for stimulation on the dura was lower than that for stimulation on the bone, especially below $3 \mathrm{kHz}$.

\section{Conclusion}

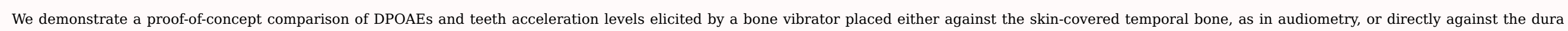

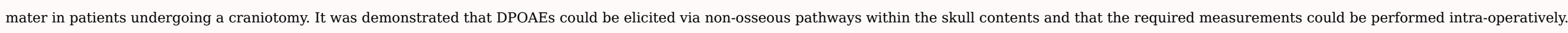




\section{Introduction}

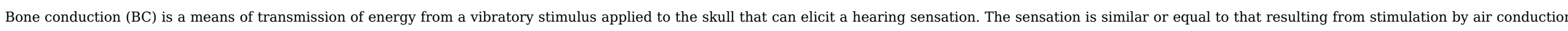

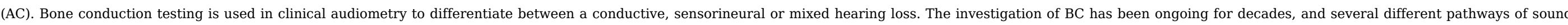

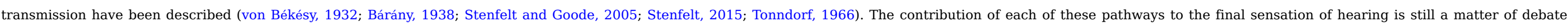

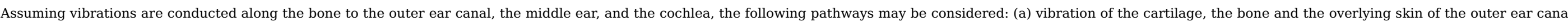

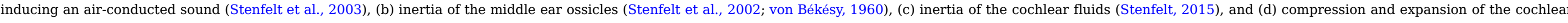

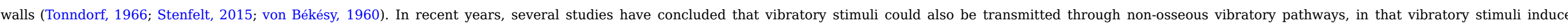

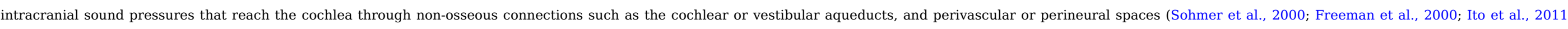

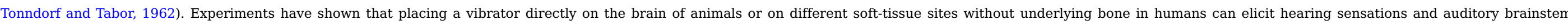

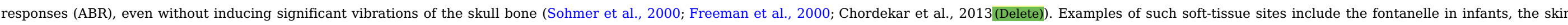

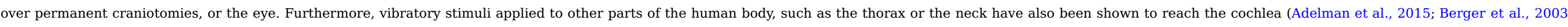
Ravicz and Melcher, 2001).

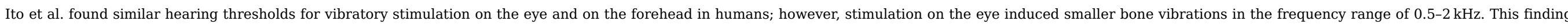

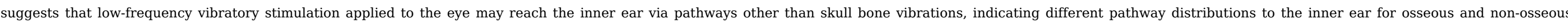

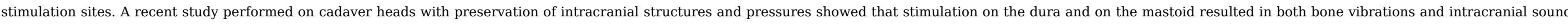

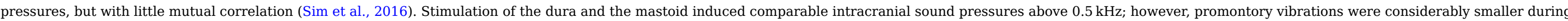
dural stimulations. Dural stimulation below $0.5 \mathrm{kHz}$ elicited higher intracranial sound pressures than stimulation on the mastoid.

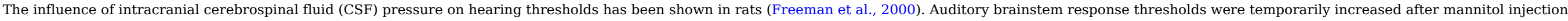

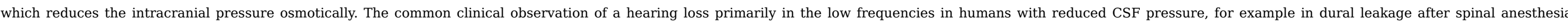

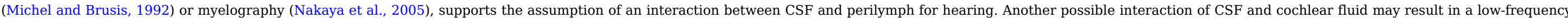

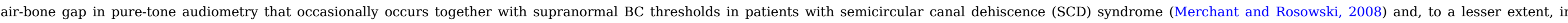

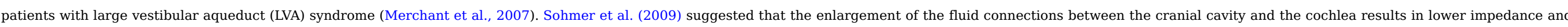

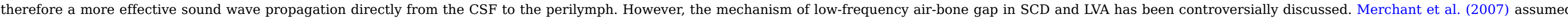

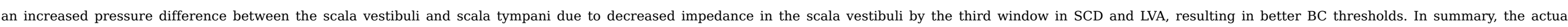
contribution of such non-osseous pathways to hearing is still controversial.

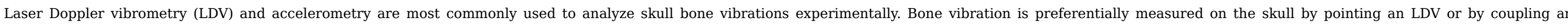

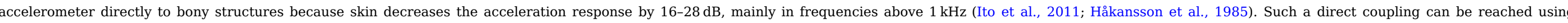

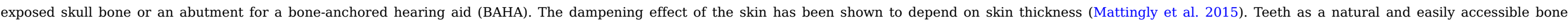

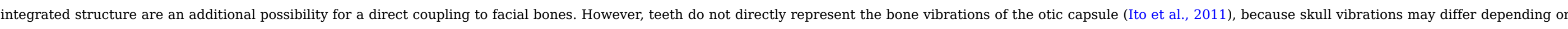
location on the skull. Teeth have been identified as an adequate site for BC stimulation in assessment and use of a vibratory BAHA (Stenfelt and Håkansson, 1999)

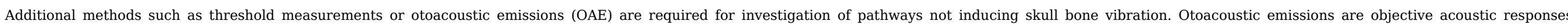

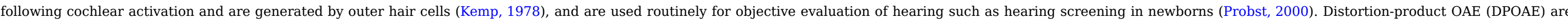

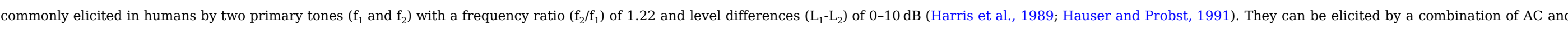

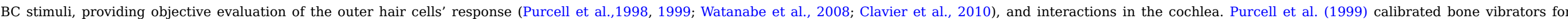




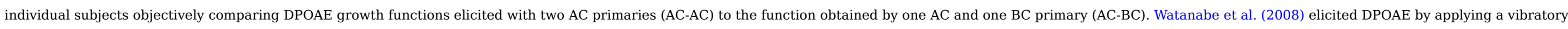
stimulus to the eye, yielding comparable DPOAE responses as with vibratory stimulation to the forehead. None of these studies measured the skull vibrations induced by BC stimuli to elicit DPOAE.

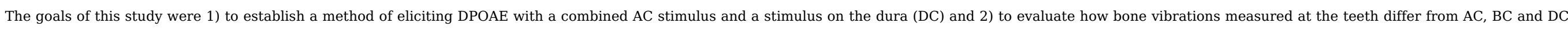

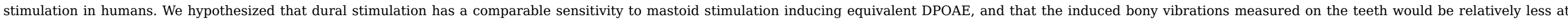

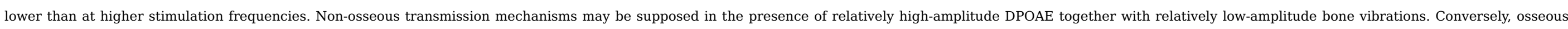
transmission mechanisms seem more likely in the presence of relatively low DPOAE and high vibration amplitudes.

\section{Materials and methods}

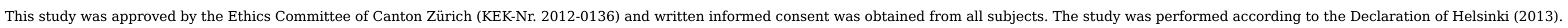

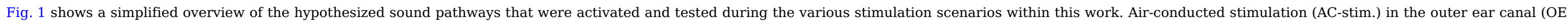

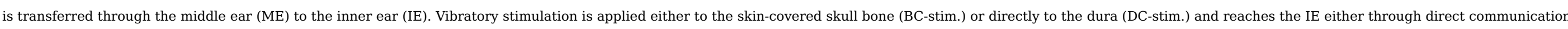

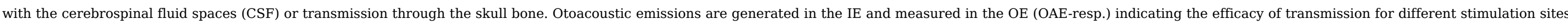
while teeth acceleration represents the skull bone vibrations (Acc-resp.). Solid lines represent the main pathways and dotted lines illustrate alternative pathways of sound conduction.

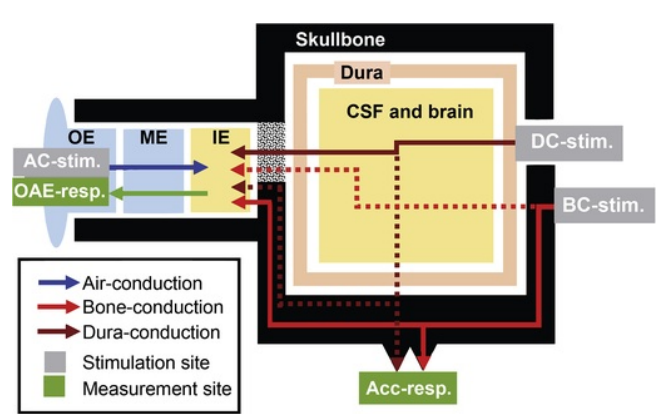

Fig. 1 Model of underlying sound pathways and measurement setup. alt-text: Fig. 1

\subsection{Subjects}

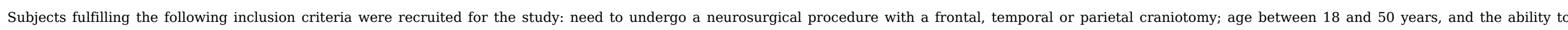

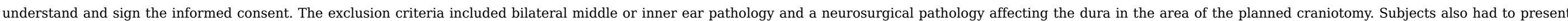
with healthy front teeth to facilitate the acceleration measurements.

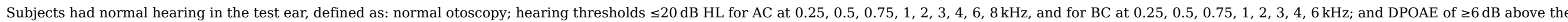

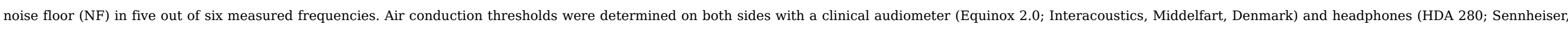

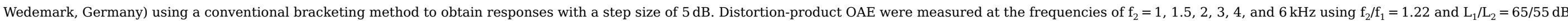

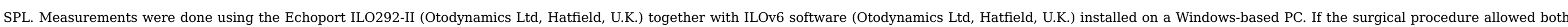
ears to be considered for intraoperative testing and both fulfilled the inclusion criteria, then the ear with the higher signal-to-noise ratio (SNR) in the DPOAE measurement was chosen.

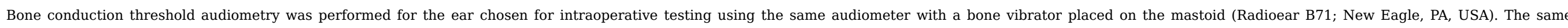
conventional bracketing method as described above was used. During this procedure, wide-band masking of $40 \mathrm{~dB}$ HL was applied to the contralateral ear using headphones.

\subsection{Measurement setup}




\subsubsection{Signal I/O hardware}

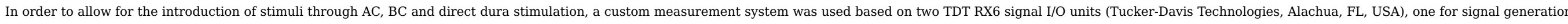

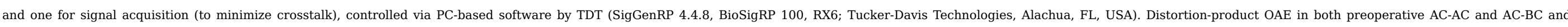

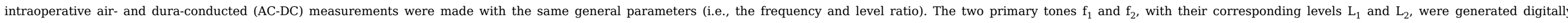

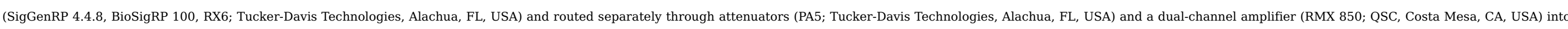

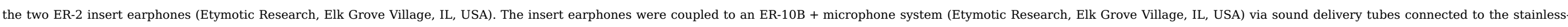

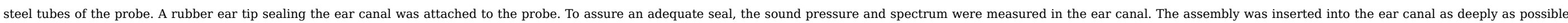
without any additional fixation to the auricle.

\subsubsection{DPOAE recording and processing}

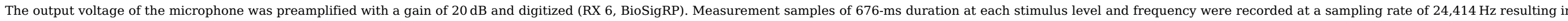

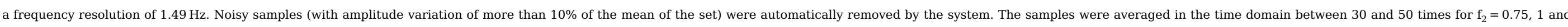

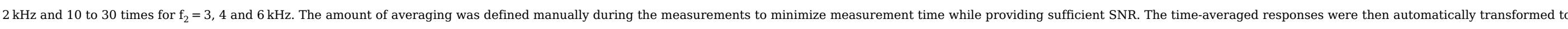

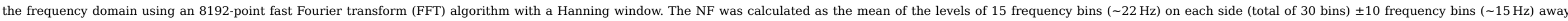
from the $2 \mathrm{f}_{1}-\mathrm{f}_{2}$ frequency, which was the only analyzed DPOAE frequency in this study.

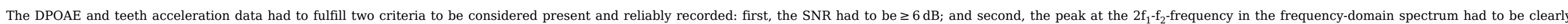

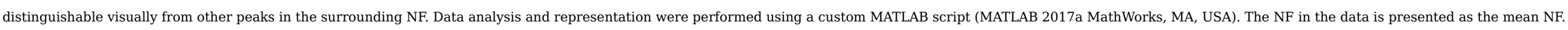

\subsubsection{Stimuli}

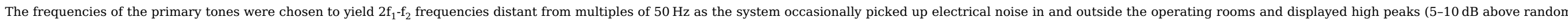

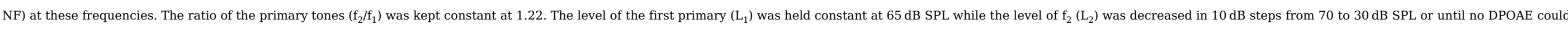

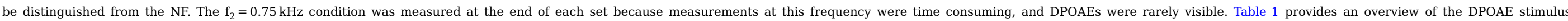
parameters.

Table 1 Overview of DPOAE stimulus parameters and corresponding $2 f_{1}-f_{2}$ frequencies.

alt-text: Table 1

\begin{tabular}{|c|c|c|c|c|}
\hline \multicolumn{2}{|c|}{ Primary tone 1} & \multicolumn{2}{|c|}{ Primary tone 2} & \multirow[t]{2}{*}{ Frequency at $2 \mathrm{f}_{1}-\mathrm{f}_{2}[\mathrm{~Hz}]$} \\
\hline Frequency $\mathrm{f}_{1}[\mathrm{~Hz}]$ & Level $\mathrm{L}_{1}$ [dB SPL] & Frequency $\mathrm{f}_{2}[\mathrm{~Hz}]$ & Level $\mathrm{L}_{2}[\mathrm{~dB}$ SPL] & \\
\hline 611.02 & 65 & 745.15 & $70,60,50,40,30$ & 476.89 \\
\hline 867.35 & 65 & 1058.11 & $70,60,50,40,30$ & 676.59 \\
\hline 1636.35 & 65 & 1994.02 & $70,60,50,40,30$ & 1278.68 \\
\hline 2470.91 & 65 & 3013.08 & $70,60,50,40,30$ & 1928.74 \\
\hline 3302.50 & 65 & 4029.77 & $70,60,50,40,30$ & 2575.23 \\
\hline 4903.08 & 65 & 5982.06 & $70,60,50,40,30$ & 3824.10 \\
\hline
\end{tabular}

\subsubsection{Bone and dura stimulation}

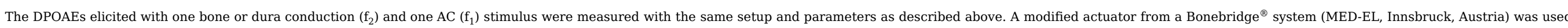




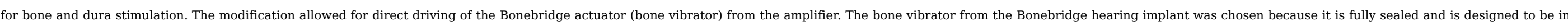
full contact with bone. A custom holder was coupled to the bone vibrator enabling it to be held in contact with the temporal region via a $5 \mathrm{~N}$ steel headband for the preoperatively measured AC-BC DPOAE (Fig. $2 \mathrm{~A}$ ).
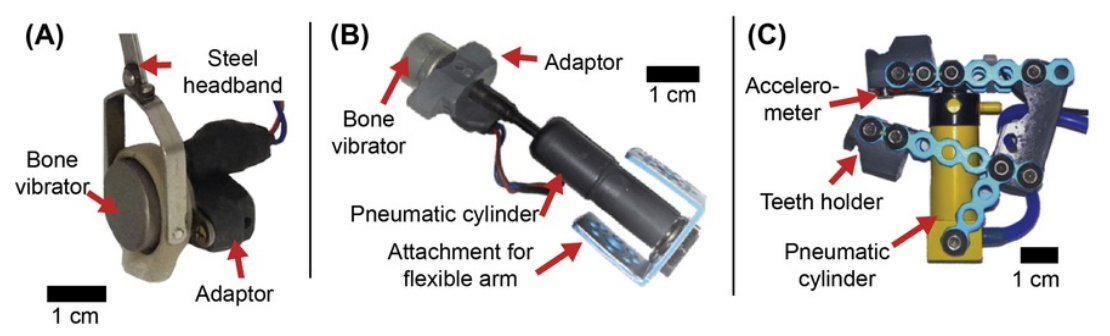

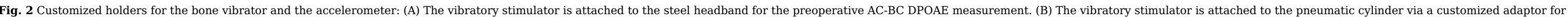
the intraoperative AC-DC DPOAE measurement. (C) The accelerometer is firmly inserted into the customized teeth holder that is pressed against the upper incisor teeth.

\section{alt-text: Fig. 2}

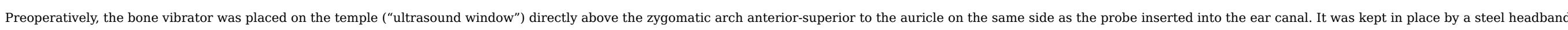
providing a static force of 5 Nente the temporal region displayed higher reproducibility of the calibrating values in comparison to the mastoid in accordance with the studies by Watanabe et al. (2008) and Ito et al. (2011).

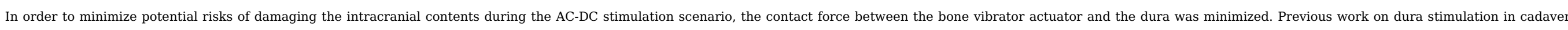

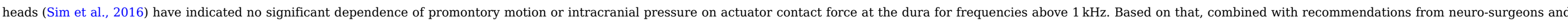

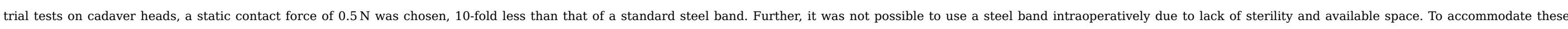

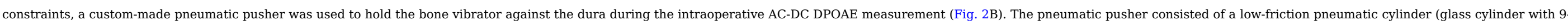

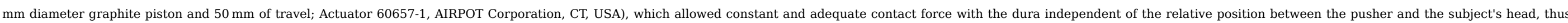

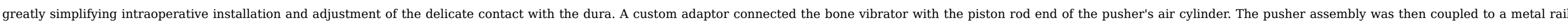

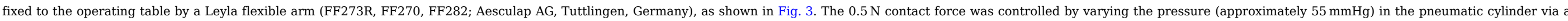

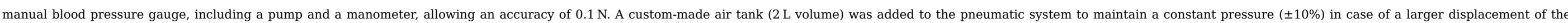

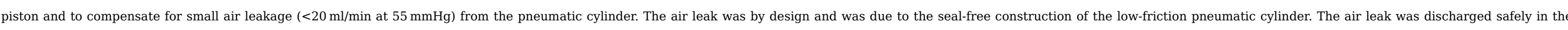
protective sleeve away from the patient and, based on trial measurements, did not affect the acoustic or vibration measurements in any detectable manner.

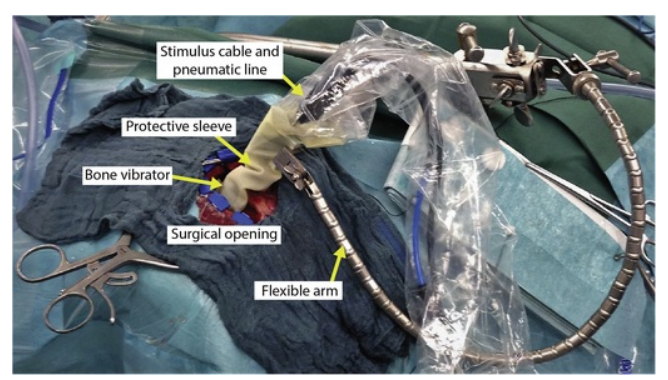

Fig. 3 Intraoperative dura stimulation. The bone vibrator is attached to the pneumatic cylinder viatia a customized adaptor and covered with a sterile bag. The assembly is attached to the operating table viatia a sterile Leyla flexible fixation arm. alt-text: Fig. 3 


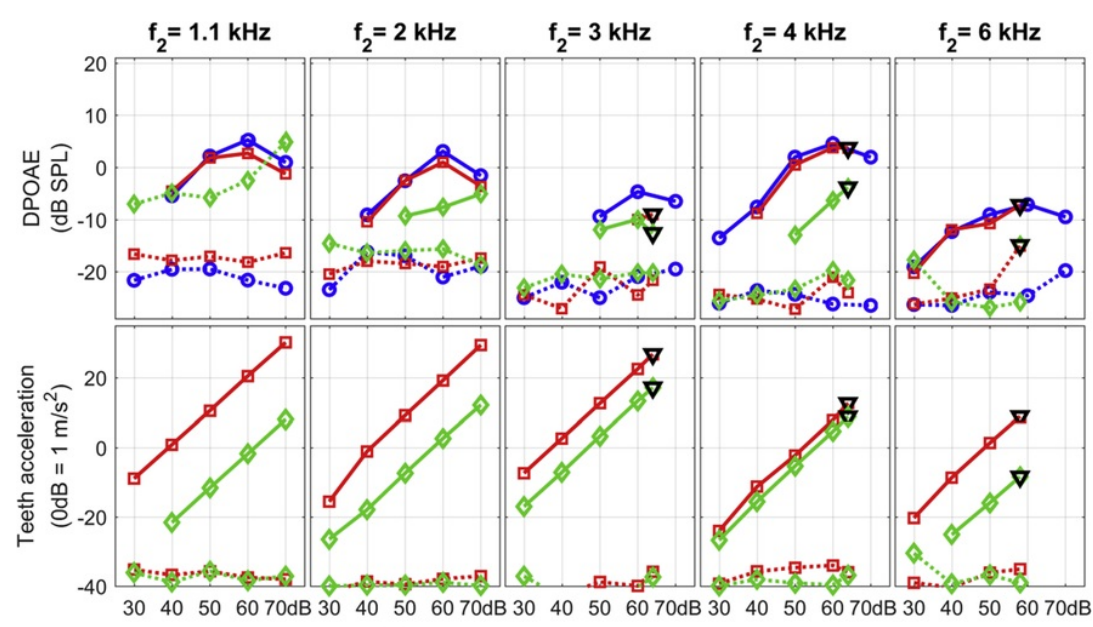

๑AC-AC $\frac{\text { Stimulus type }}{\square-A C-B C} \triangleq A C-D C \quad$ C..... Noise $\nabla$ Stim. Clip.

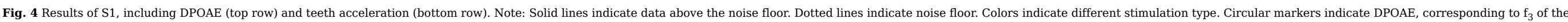

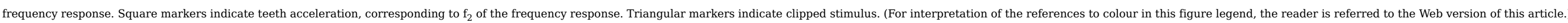
alt-text: Fig. 4

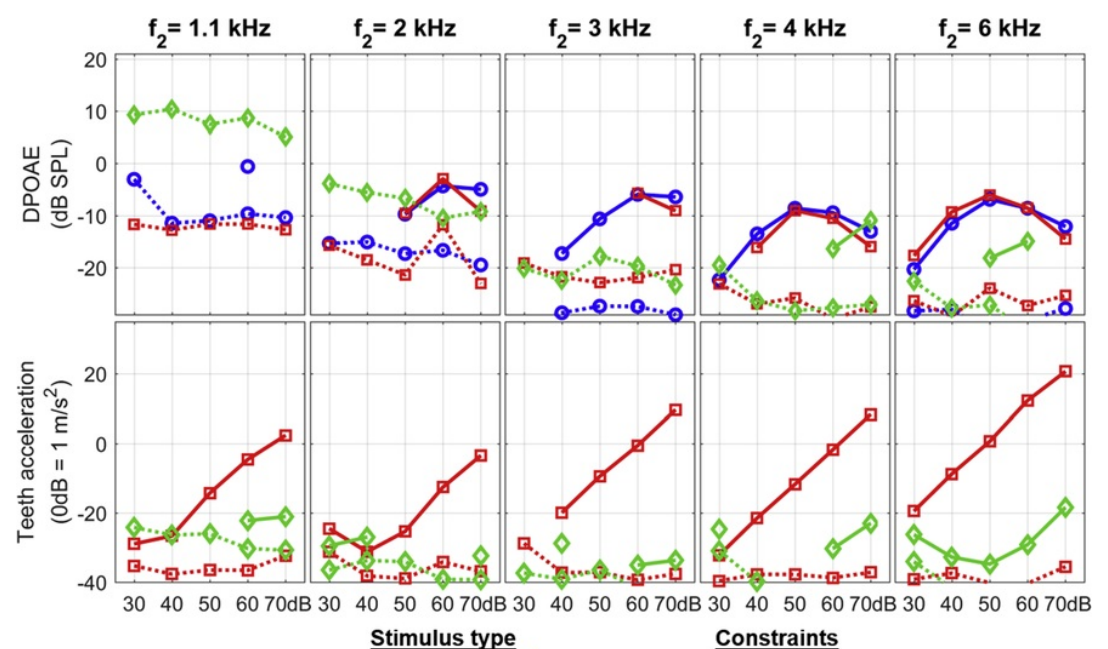

-AC-AC $\frac{\text { Stimulus type }}{\square-A C-B C} \leadsto$ AC-DC $\quad$...... Noise $\nabla$ Stim. Clip.

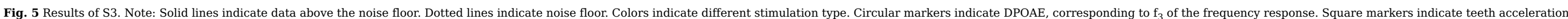
corresponding to $\mathrm{f}_{2}$ of the frequency response. Triangular markers indicate clipped stimulus. (For interpretation of the references to colour in this figure legend, the reader is referred to the Web version of this article.) 


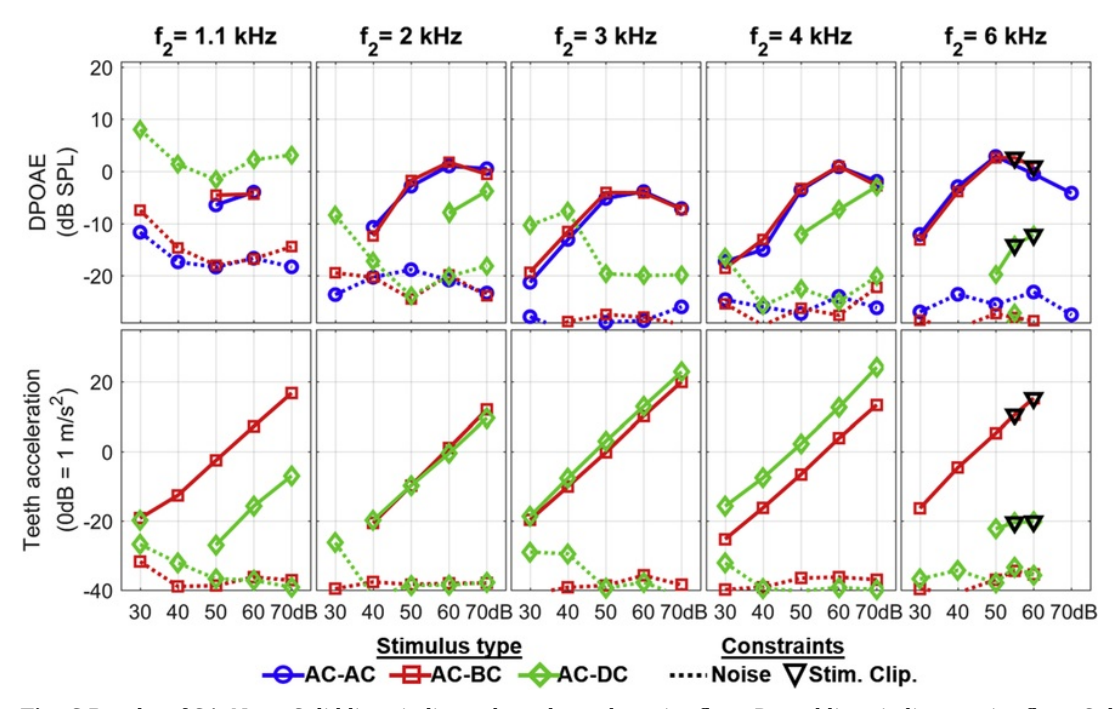

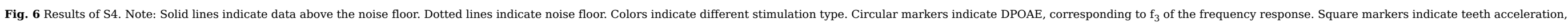
corresponding to $\mathrm{f}_{2}$ of the frequency response. Triangular markers indicate clipped stimulus. (For interpretation of the references to colour in this figure legend, the reader is referred to the Web version of this article.) alt-text: Fig. 6

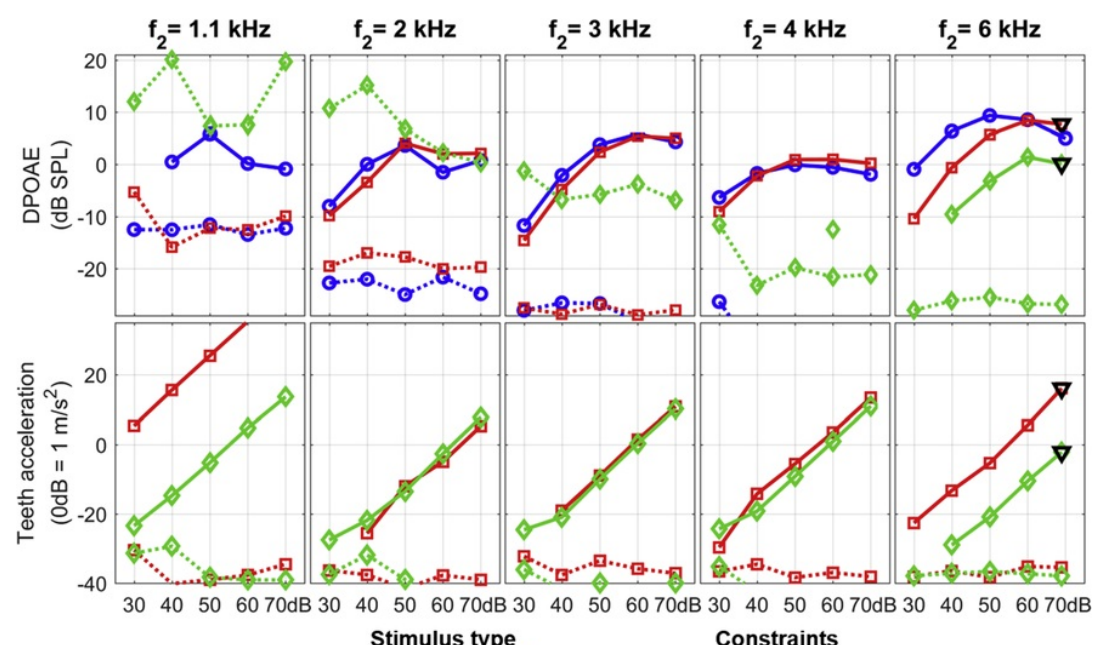

$\rightarrow$ AC-AC $\frac{\text { Stimulus type }}{\square \text { AC-BC }} \leadsto$ AC-DC $\quad$...... Noise $\nabla$ Stim. Clip.

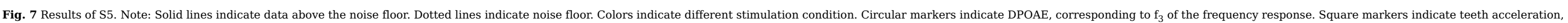
corresponding to $\mathrm{f}_{2}$ of the frequency response. Triangular markers indicate clipped stimulus. (For interpretation of the references to colour in this figure legend, the reader is referred to the Web version of this article.) 


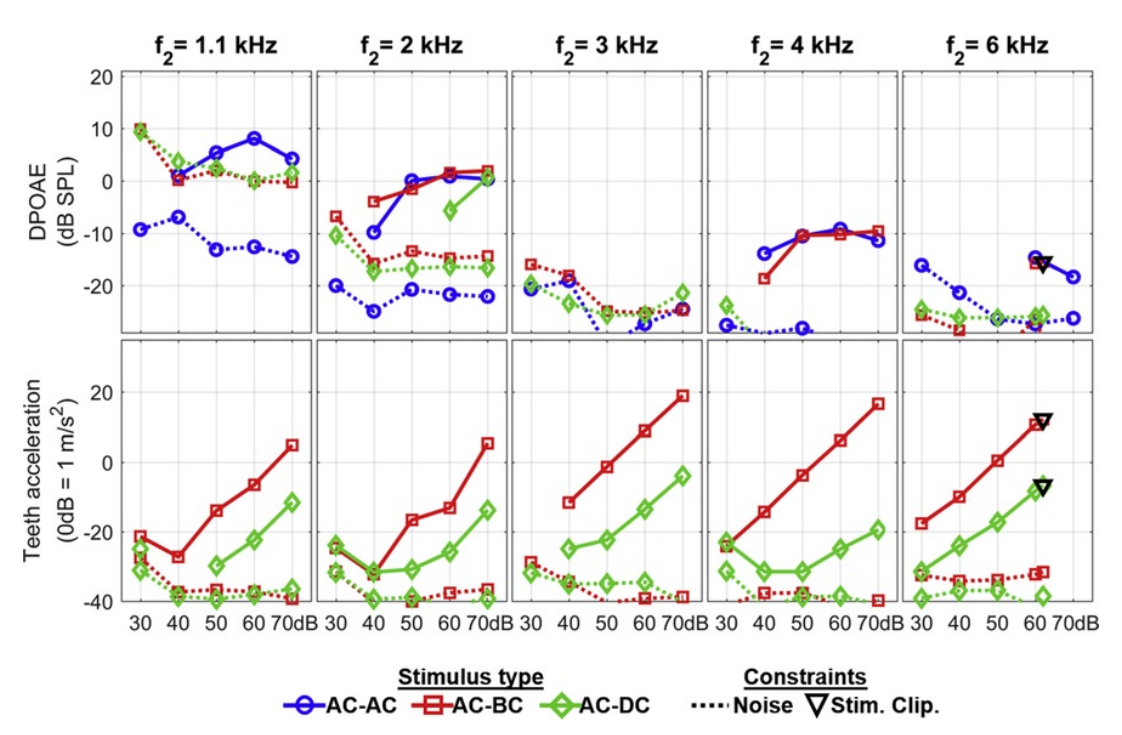

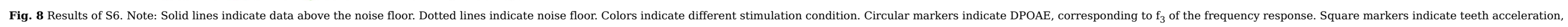
corresponding to $\mathrm{f}_{2}$ of the frequency response. Triangular markers indicate clipped stimulus. (For interpretation of the references to colour in this figure legend, the reader is referred to the Web version of this article.)

\subsubsection{Teeth acceleration}

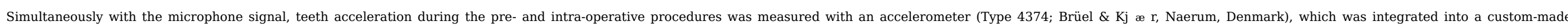

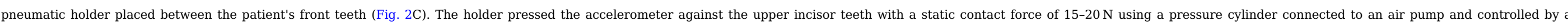

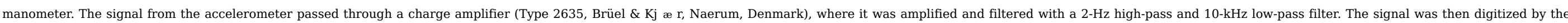

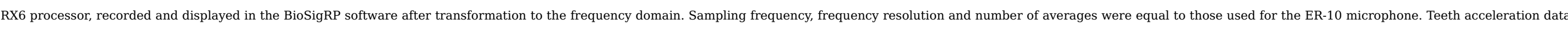
reported in this work are based on the magnitude of the accelerometer signal at the $\mathrm{f}_{2}$ frequency, indicative of the bone conduction component of the BC and DC stimulation.

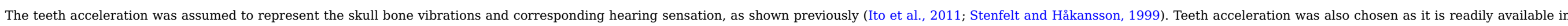

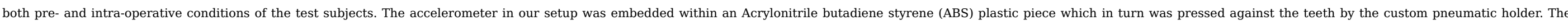

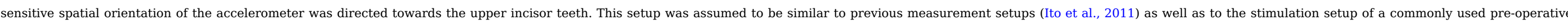

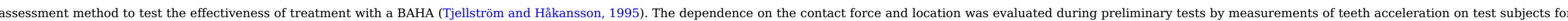

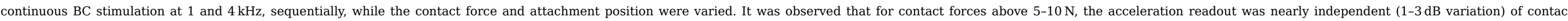

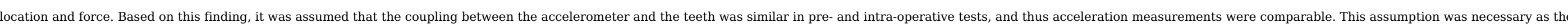
patient's or surgeon's control over the contact force during the intraoperative measurements was impossible due to the anesthetization and sterile covering.

\subsubsection{Calibration of the measurement setup}

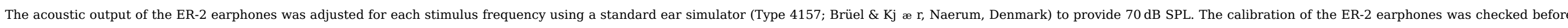

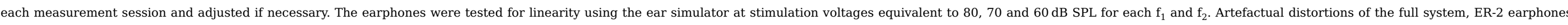

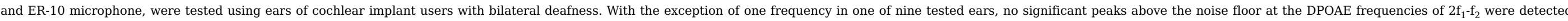

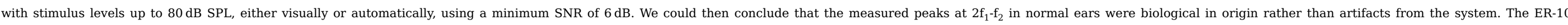
microphone's linearity was successfully tested in the range from $=-20$ to $100 \mathrm{~dB}$ SPL in the anechoic test chamber (Type 4222; Brüel \& Kj æ r, Naerum, Denmark). 


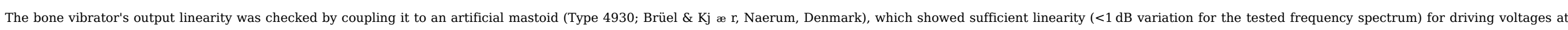

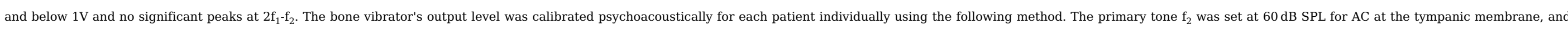

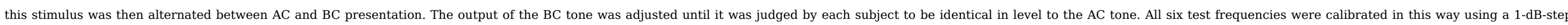

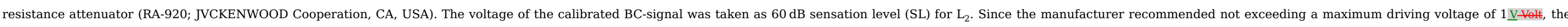

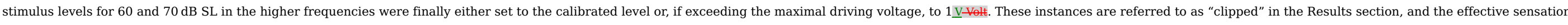

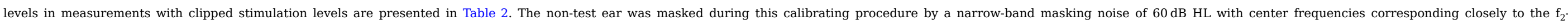
frequencies $(=-18$ to $+60 \mathrm{~Hz})$ using the audiometer with an insert earphone (E-A-RTONE ${ }^{\mathrm{TM}} 3 \mathrm{~A} ; 3 \mathrm{M}^{\mathrm{TM}}$, St. Paul, MN, USA).

Table 2 Sensation levels for $\mathrm{L}_{2}$ in measurements with clipped stimulation levels.

\section{alt-text: Table 2}

Target SL $[\mathrm{dB}]$

Subject $-\mathrm{f}_{2}$
30

30

30

30

30

30

30
40

\begin{tabular}{|l|}
40 \\
40 \\
40 \\
40 \\
40 \\
40 \\
\hline
\end{tabular}

40

40
50

\begin{tabular}{|l|}
\hline 50 \\
\hline 50 \\
\hline 50 \\
\hline 50 \\
\hline 50 \\
\hline 50 \\
\hline
\end{tabular}

60

60

58

55

60

60
70

\begin{tabular}{|l|}
\hline 66 \\
\hline 66 \\
\hline 58 \\
\hline 60 \\
\hline 69 \\
\hline 62
\end{tabular}

62

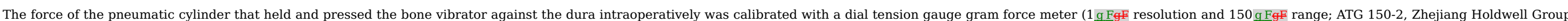
Limited, China).

\subsection{Measurement procedures}

\subsubsection{Preoperative DPOAE measurements (AC-AC and AC-BC)}

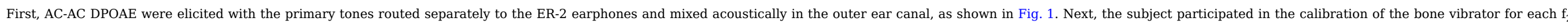

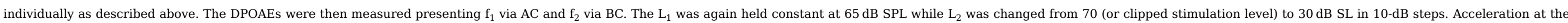

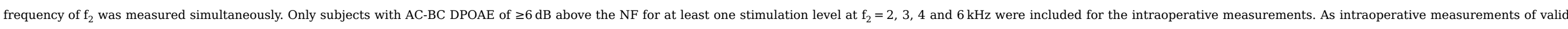

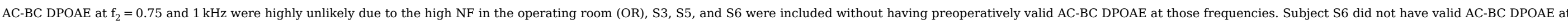

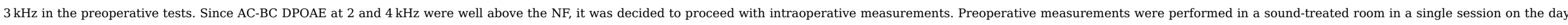
before surgery. The total measurement time was approximately 75 min for the preoperative tests, including calibration, AC-AC, and AC-BC.

\subsubsection{Intraoperative DPOAE measurement (AC-DC)}

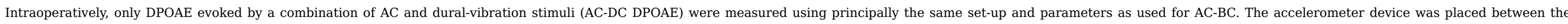

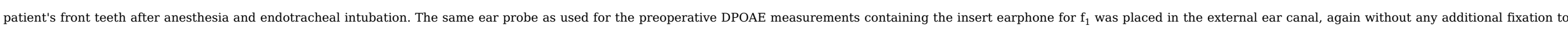

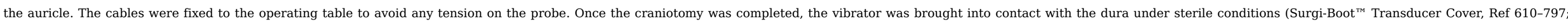

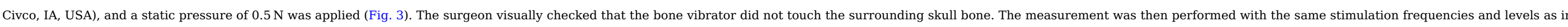

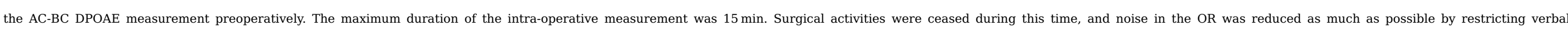




\section{Results}

\subsection{Subjects}

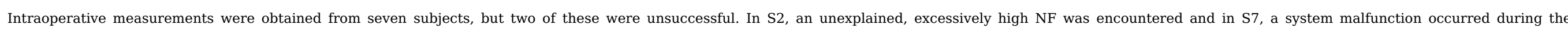

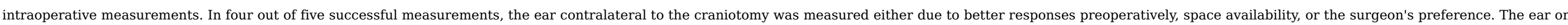
the same side as the craniotomy was tested in S5. Table 3 presents an overview of the five subjects finally included in the results.

Table 3 Characteristics of the individual subjects included for further analysis.

\section{alt-text: Table 3}

Subject

S1

S3

S4

S5

S6

\subsection{DPOAE measurements}

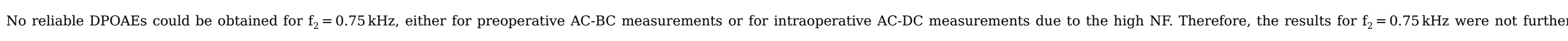
analyzed.

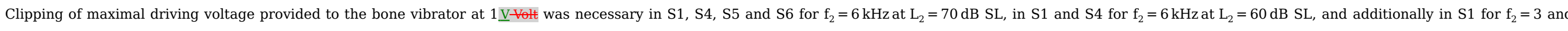

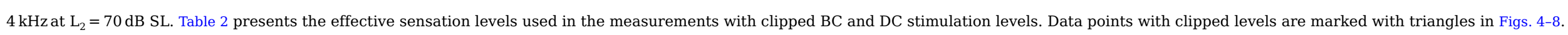

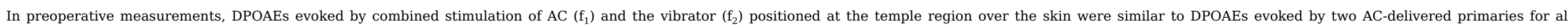
frequencies, indicating well-calibrated stimulation levels for the BC stimulator (red squares and blue circles in Figs. 4-8). No further analysis of AC-AC versus AC-BC measurements was performed.

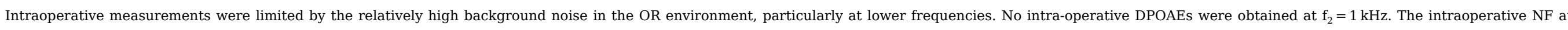

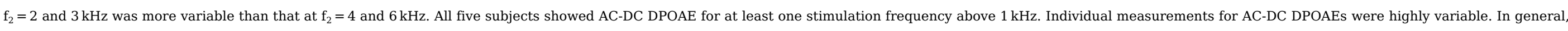

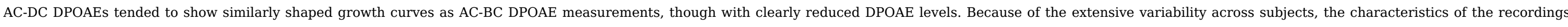
from the participants are presented individually (Figs. 4-8). Only data with an SNR of $\geq 6 \mathrm{~dB}$ and considered to be a biological response are displayed.

\subsection{Acceleration measurements}

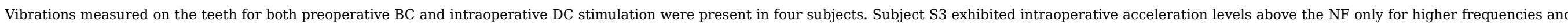

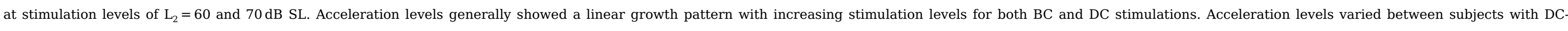
stimulation resulting in smaller, equal or even higher (S4) acceleration levels compared to BC-stimulation.

\subsection{Individual subject data}

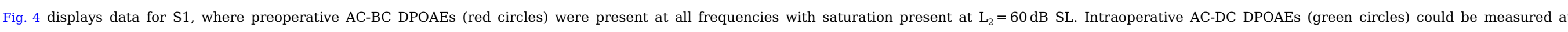

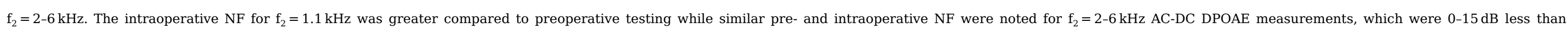




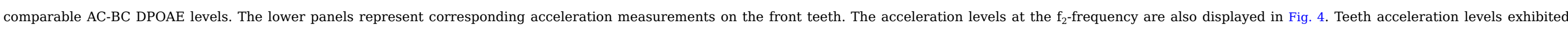

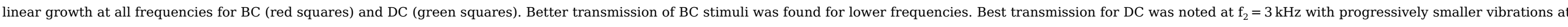

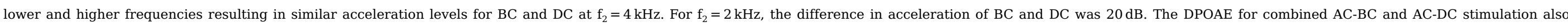
differed, as indicated on the x-axis. For stimulation at $\mathrm{f}_{2}=4 \mathrm{kHz}, \mathrm{BC}$ and DC resulted in equal acceleration levels but not in the corresponding growth functions of DPOAE levels.

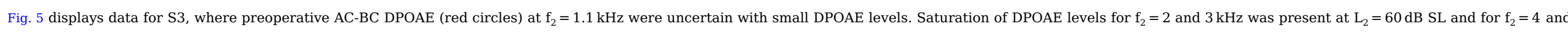

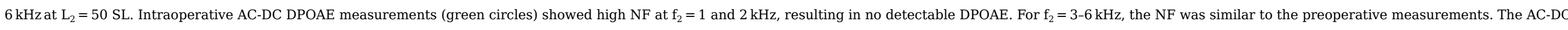

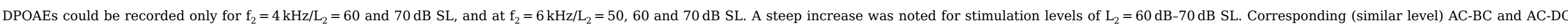
DPOAE levels are shifted by roughly $20 \mathrm{~dB}$ to the right for display purposes.

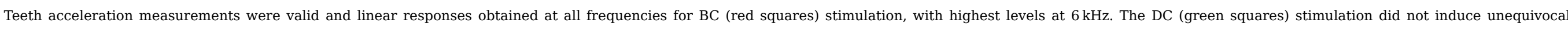
vibrations at most levels and frequencies. Teeth vibrations may have been present at $4 \mathrm{kHz} / 70 \mathrm{~dB}$ SL and $6 \mathrm{kHz} / 60$ and $70 \mathrm{~dB}$ SL.

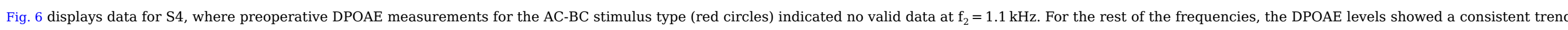

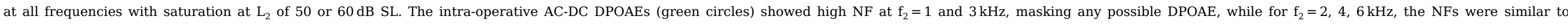

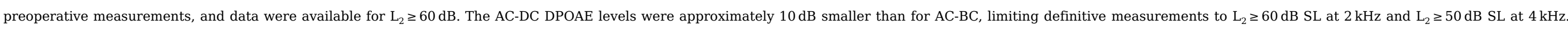
Markedly smaller DPOAE levels were present for $\mathrm{f}_{2}=6 \mathrm{kHz}$.

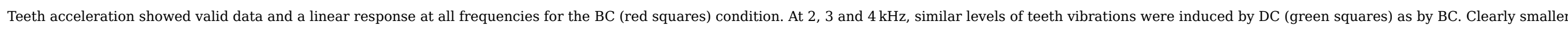

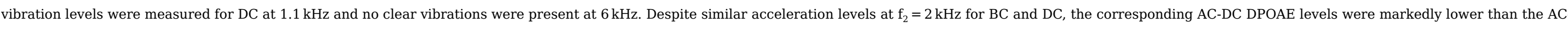
BC DPOAE levels.

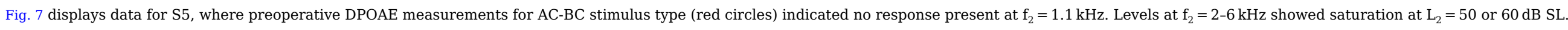

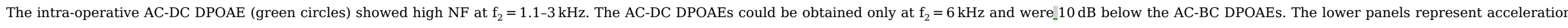
measurements on the front teeth.

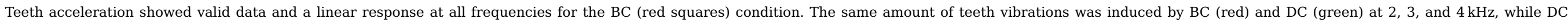

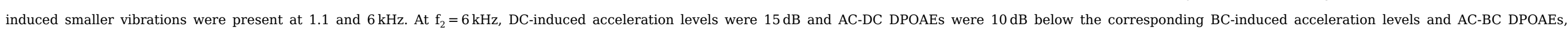
respectively. At $\mathrm{f}_{2}=4 \mathrm{kHz}$, AC-DC DPOAEs were only present for $\mathrm{L}_{2}=60 \mathrm{~dB}$ SL despite similar acceleration levels for BC and DC.

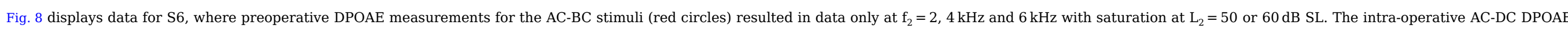
(green circles) data indicated high NF at $\mathrm{f}_{2}=1 \mathrm{kHz}$. No DPOAEs were present except at $2 \mathrm{kHz} / \mathrm{L}_{2}=60$ and $70 \mathrm{~dB}$ SL.

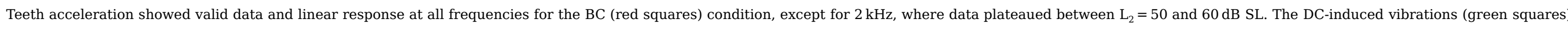
were markedly smaller compared to corresponding BC-vibrations, potentially explaining the overall poor quality of the AC-DC DPOAE data at other frequencies.

\section{Discussion}

\subsection{Experiment complexity and data variability}

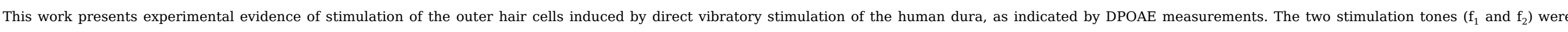

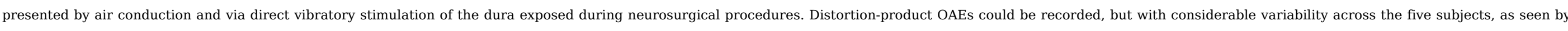

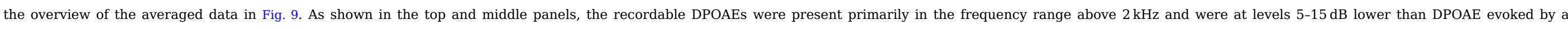
combination of AC and BC stimuli, measured preoperatively under standard audiometric conditions. The averaged data points were plotted in Fig. 9 only when data were available for at least three subjects. 

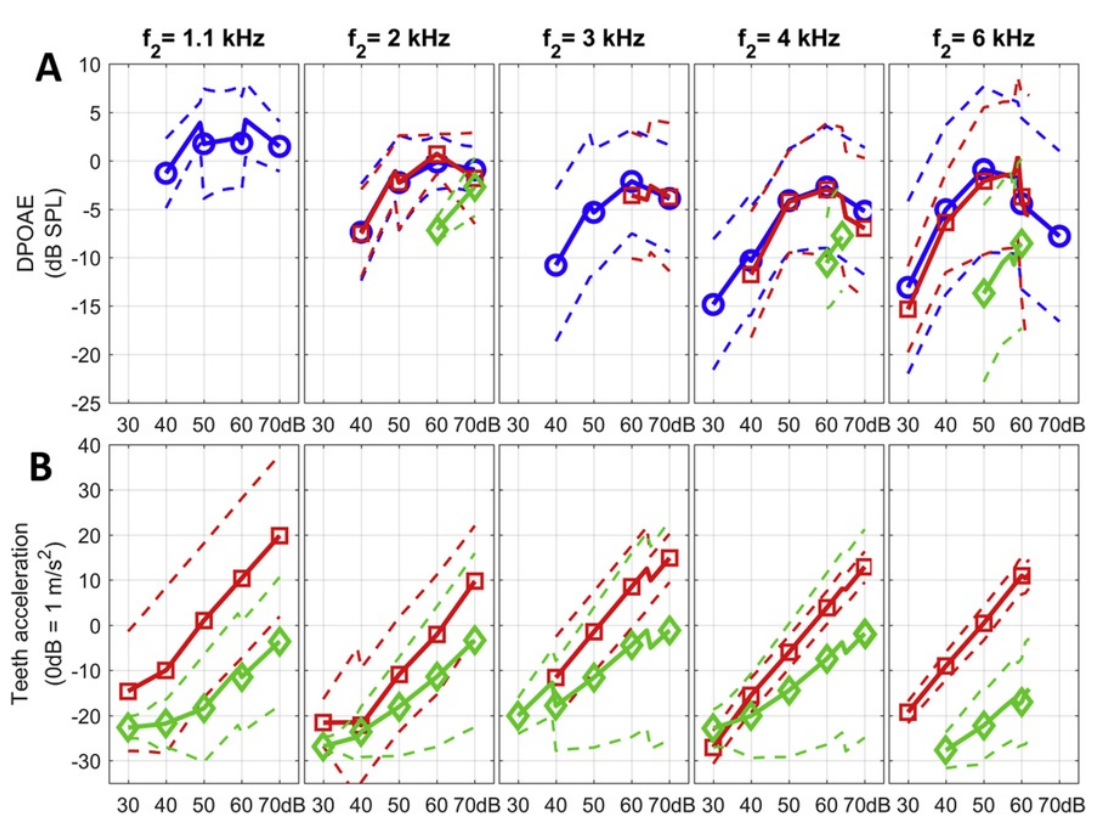

$3040506070 \mathrm{~dB} 3040506070 \mathrm{~dB} 3040506070 \mathrm{~dB} 3040506070 \mathrm{~dB} 3040506070 \mathrm{~dB}$

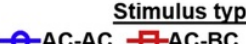

\section{Constraints}

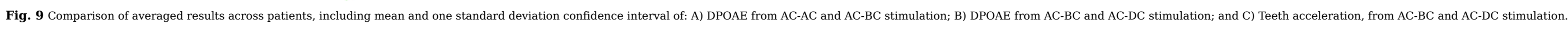

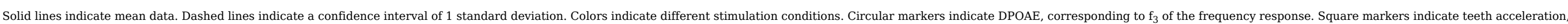
corresponding to $\mathrm{f}_{2}$ of the frequency response. (For interpretation of the references to colour in this figure legend, the reader is referred to the Web version of this article.)

\section{alt-text: Fig. 9}

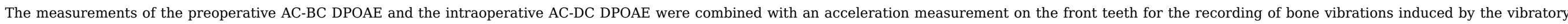

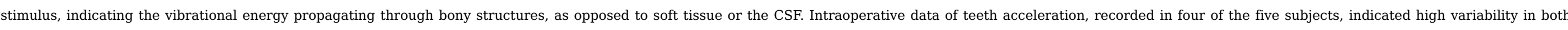
absolute levels as well as in the ratio between DC and BC stimulations, as indicated by the large (20-40 dB) confidence intervals displayed in Fig. 9 (bottom).

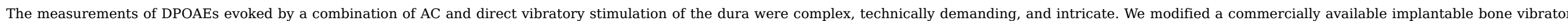

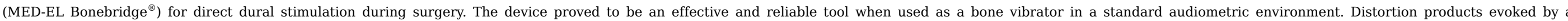

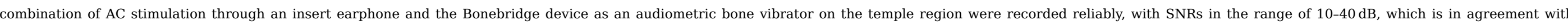

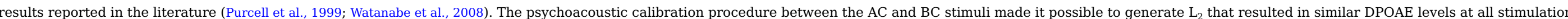
levels and frequencies, as seen in Fig. 9A.

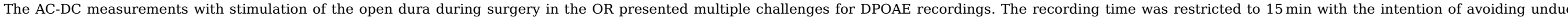

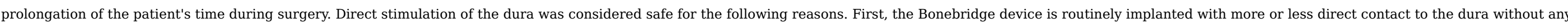

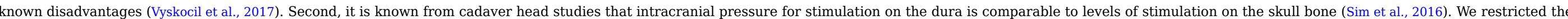
stimulation level equivalent to no more than $70 \mathrm{~dB}$ SL. Finally, the pressure on the dura was kept at a low level of $0.5 \mathrm{~N}$ and direct contact to brain structures was avoided.

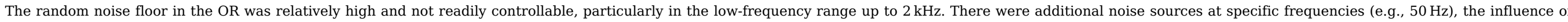

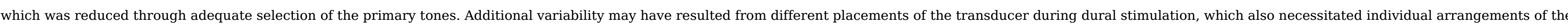

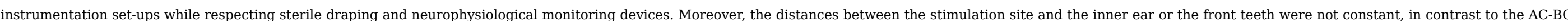




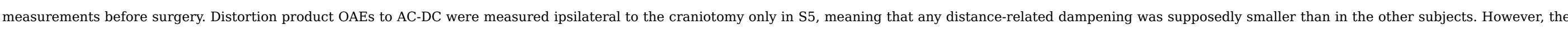

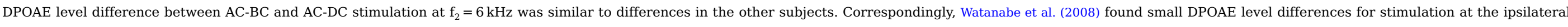

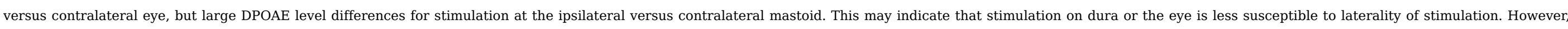
this may need further experimental verification.

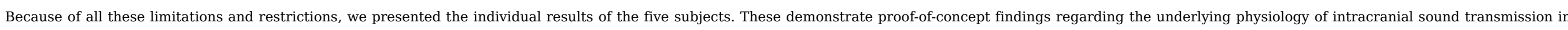
humans. Predictably, results were highly variable, and we were not able to fit them to a consistent pattern. This is clearly evident by comparing the data in Fig. 9 with the individual displays in Figs. 4-8.

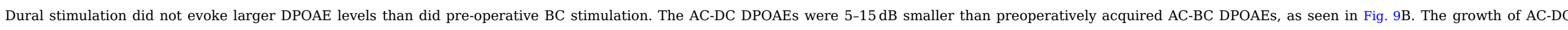
DPOAE levels with increasing stimulation levels seemed to be similar to that of AC-BC DPOAEs, but saturation was often not reached because the stimulus level was limited.

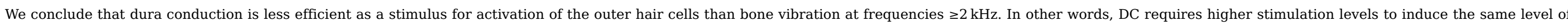

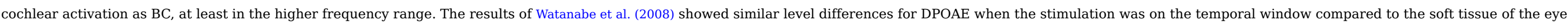

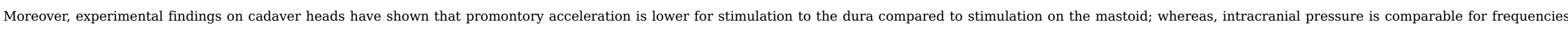

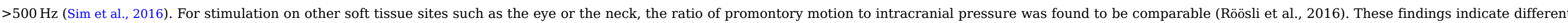
stimulations of the skull bone and intracranial contents from vibratory stimulation at different soft tissue sites.

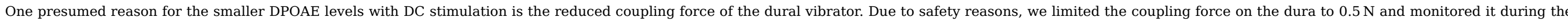

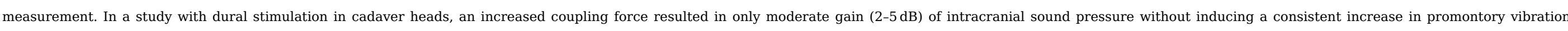

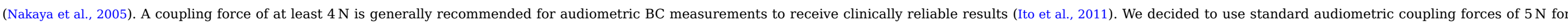

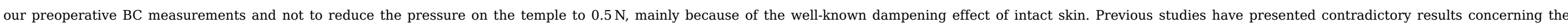

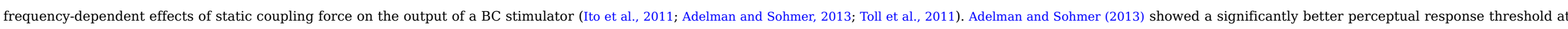

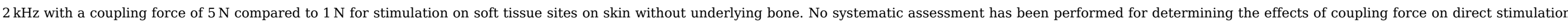

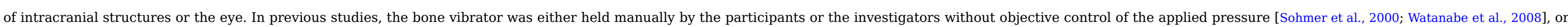

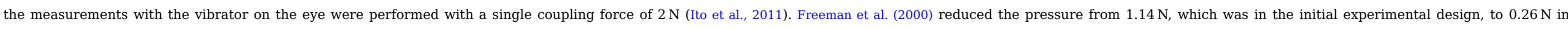

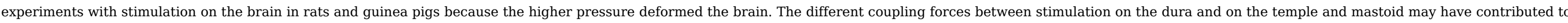
DPOAE differences. This constitutes an obvious limitation of this study.

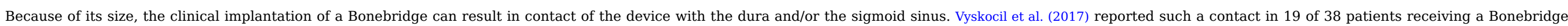

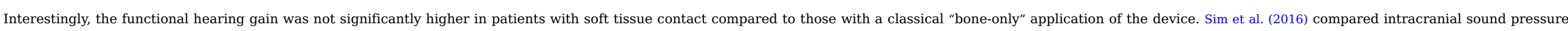

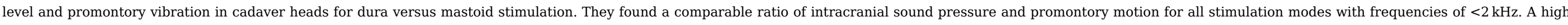
noise level made it impossible to draw conclusions in the frequency range $<2 \mathrm{kHz}$. Our study had limitations in measurement capabilities for the low frequencies.

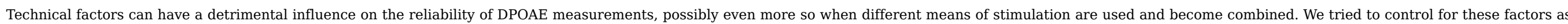

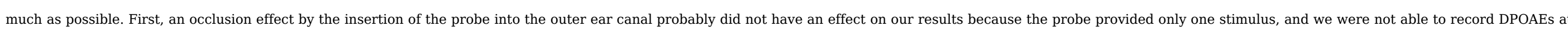

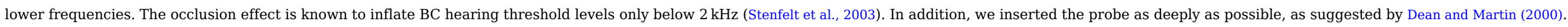

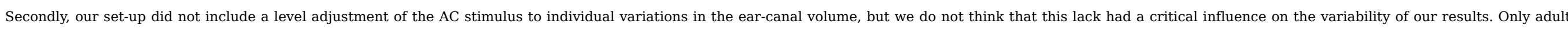

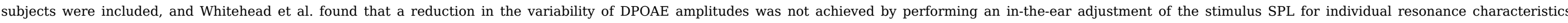
(Whitehead et al., 1995).

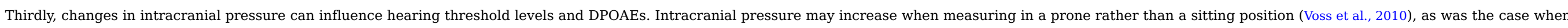

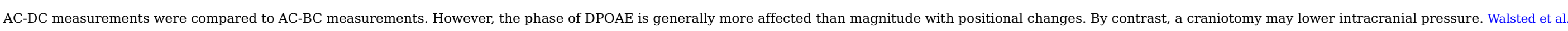




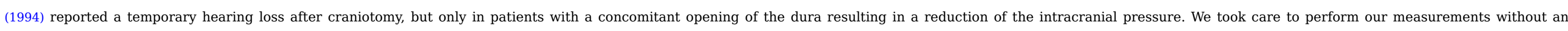

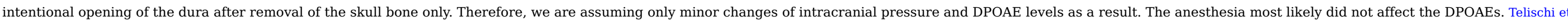

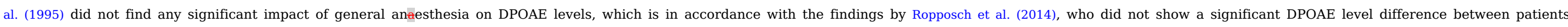
anesthetized with sevoflurane and those with propofol for $\mathrm{f}_{2}$ between 2 and $8 \mathrm{kHz}$.

Fourthly, it was not possible to match the actual loudness of dura stimulation to the AC or BC stimulus. Stimulus levels applied to the dura may have differed to an unknown extent.

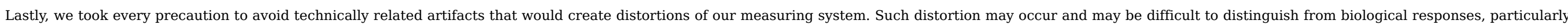

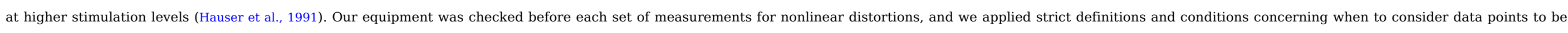
valid DPOAE recordings.

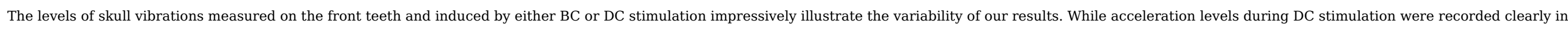

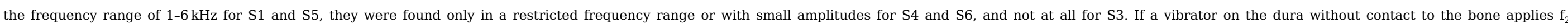

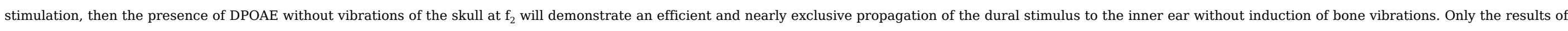

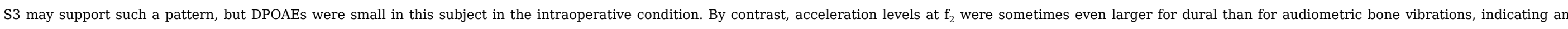

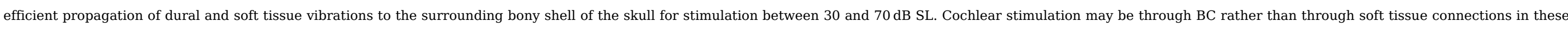

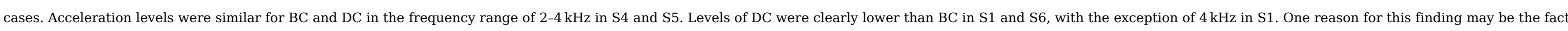

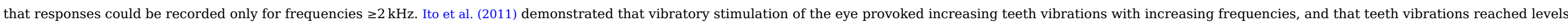
similar to standard audiometric BC stimulation levels at about $2 \mathrm{kHz}$. Vibration levels also became more variable at higher frequencies, just as in our subjects.

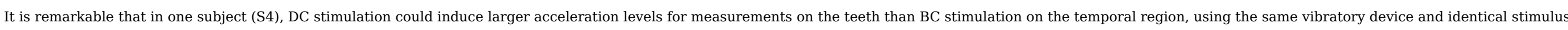

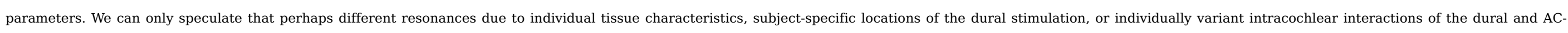

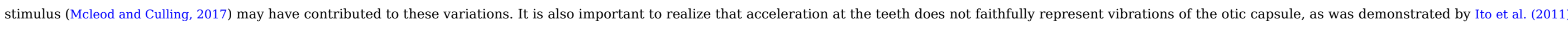

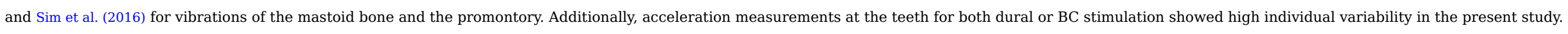

\section{Conclusion}

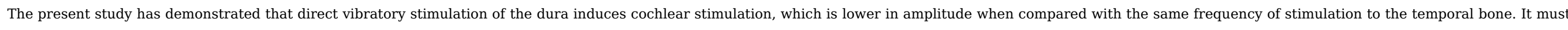

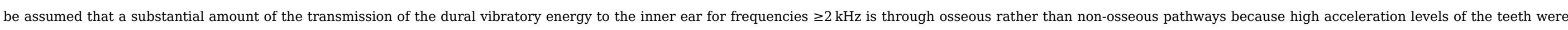

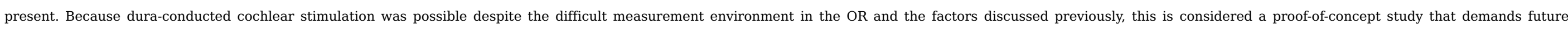
research be conducted to investigate the characteristics of DPOAE with dural stimulation, in particular for lower frequency and threshold level stimuli.

\section{Funding}

This research did not receive any specific grant monies from funding agencies in the public, commercial, or not-for-profit sectors.

\section{Uncited References}

World Medical Association, 2013.

\section{Acknowledgments}

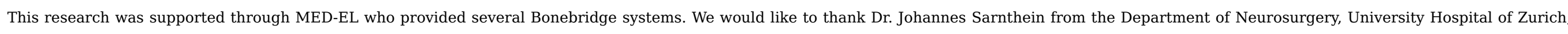
for technical support and the staff from the neurosurgical operating theater.

\section{References}




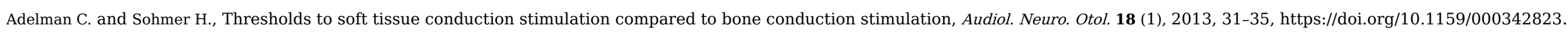

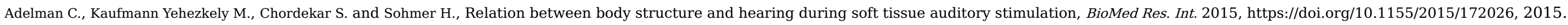

Bárány E., A contribution to the physiology of bone conduction, Acta Otolaryngol. 26, 1938, 1-223.

von Békésy G., Zur Theorie des Hörens bei der Schallaufnahme durch Knochenleitung, Ann. Phys. 405, 1932, 111-136, https://doi.org/10.1002/andp19324050109.

von Békésy G., Experiments in Hearing, 1960, McGraw-Hill; New York.

Berger E.H., Kieper R.W. and Gauger D., Hearing protection: surpassing the limits to attenuation imposed by the bone-conduction pathways, J. Acoust. Soc. Am. 114 (4), 2003, 1955-1967.

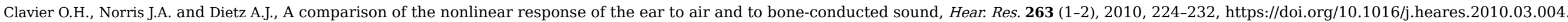
Dean M.S. and Martin F.N., Insert earphone depth and the occlusion effect, Am. J. Audiol. 9 (2), 2000, 131-134.

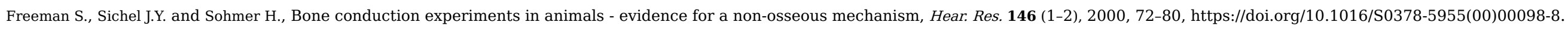

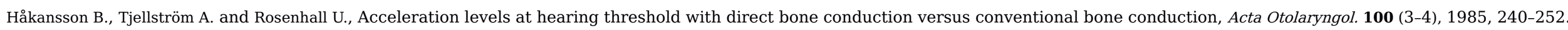

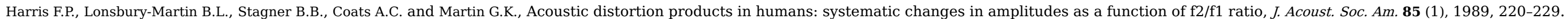

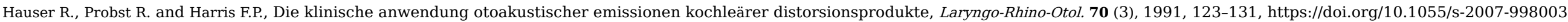

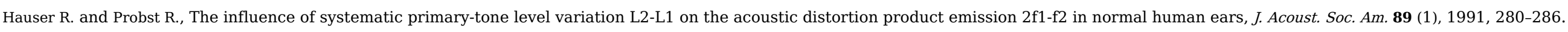

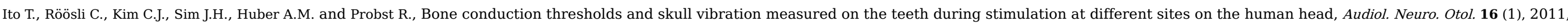

12-22, https://doi.org/10.1159/000314282.

Kemp D.T., Stimulated acoustic emissions from within the human auditory system, J. Acoust. Soc. Am. 64 (5), 1978, $1386-1391$.

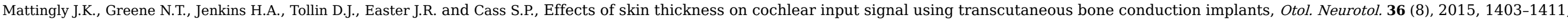

https://doi.org/10.1097/MAO.0000000000000814.

Mcleod R.W. and Culling J.F., Measurements of inter-cochlear level and phase differences of bone-conducted sound, J. Acoust. Soc. Am. 141 (5), $2017,3421-3429$.

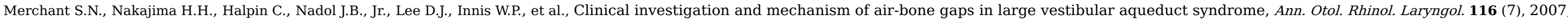

532-541, https://doi.org/10.1177/000348940711600709

Merchant S.N. and Rosowski J.J., Conductive hearing loss caused by third-window lesions of the inner ear, Otol. Neurotol. 29 (3), 2008, 282-289, https://doi.org/10.1097/mao.0b013e318161ab24.

Michel O. and Brusis T., Hearing loss as a sequel of lumbar puncture, Ann. Otol. Rhinol. Laryngol. 101 (5), 1992, 390-394, https://doi.org/10.1177/000348949210100503.

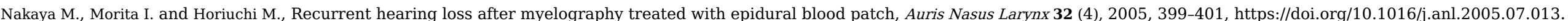

Probst R., Das diagnostische Spektrum der OAE, Laryngo-Rhino-Otol. 79 (11), 2000, 631-632, https://doi.org/10.1055/s-2000-8297.

Purcell D., Kunov H. and Cleghorn W., Objective calibration of bone conductors using otoacoustic emissions, Ear Hear. 20 (5), 1999, 375-392.

Purcell D., Kunov H., Madsen P. and Cleghorn W., Distortion product otoacoustic emissions stimulated through bone conduction, Ear Hear. 19 (5), $1998,362-370$.

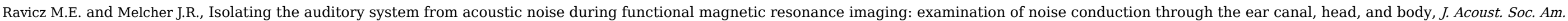
109 (1), 2001, 216-231. 


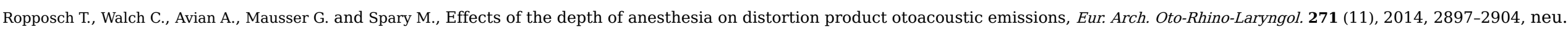

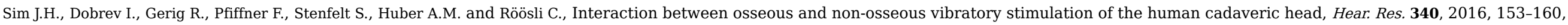

https://doi.org/10.1016/j.heares.2016.01.013.

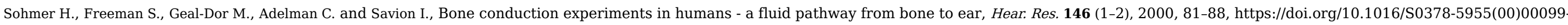
$\mathrm{X}$.

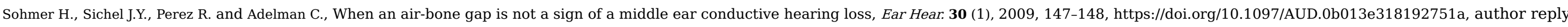
$148-9$.

Stenfelt S. and Goode R.L., Bone-conducted sound: physiological and clinical aspects, Otol. Neurotol. 26 (6), 2005, 1245-1261.

Stenfelt S., Hato N. and Goode R.L., Factors contributing to bone conduction: the middle ear, J. Acoust. Soc. Am. 111 (2), 2002, 947-959, https://doi.org/10.1121/1.1432977.

Stenfelt S., Wild T., Hato N. and Goode R.L., Factors contributing to bone conduction: the outer ear, J. Acoust. Soc. Am. 113 (2), 2003, 902-913, https://doi.org/10.1121/1.1534606.

Stenfelt S., Inner ear contribution to bone conduction hearing in the human, Hear. Res. 329, 2015, 41-51, https://doi.org/10.1016/j.heares.2014.12.003.

Stenfelt S.P. and Håkansson B.E., Sensitivity to bone-conducted sound: excitation of the mastoid vs the teeth, Scand. Audiol. 28 (3), 1999, $190-198$.

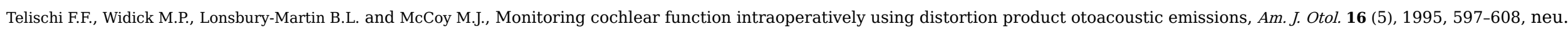

Tjellström A. and Håkansson B., The bone-anchored hearing aid. Design principles, indications, and long-term clinical results, Otolaryngol. Clin. 28 (1), $1995,53-72$.

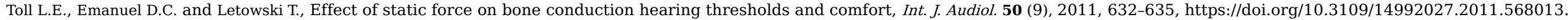

Tonndorf J., Bone conduction studies in experimental animals, Acta Otolaryngol. 132 (Suppl. 213), 1966, 7-9.

Tonndorf J. and Tabor J.R., Closure of the cochlear windows: its effect upon air- and bone-conduction, Ann. Otol. Rhinol. Laryngol. 71, 1962, 5-29, https://doi.org/10.1177/000348946207100101.

Voss S.E., Adegoke M.F., Horton N.J., Sheth K.N., Rosand J. and Shera C.A., Posture systematically alters ear-canal reflectance and DPOAE properties, Hear. Res. 263 (1-2), 2010, 43-51,

https://doi.org/10.1016/j.heares.2010.03.003.

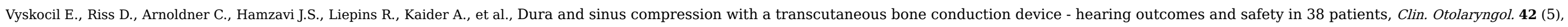
2017, 1033-1038, https://doi.org/10.1111/coa.12793.

Walsted A., Nielsen O.A. and Borum P., Hearing loss after neurosurgery. The influence of low cerebrospinal fluid pressure, J. Laryngol. Otol. 108 (8), $1994,637-641$.

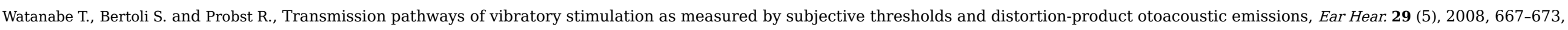

https://doi.org/10.1097/AUD.0b013e3181775dde.

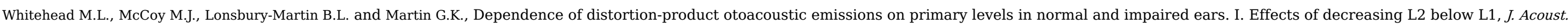
Soc. Am. 97 (4), 1995, 2346-2358.

World Medical Association, World Medical Association Declaration of Helsinki: ethical principles for medical research involving human subjects, J. Am. Med. Assoc. 310 (20), 2013, 2191-2194,

https://doi.org/10.1001/jama.2013.281053.

\section{Highlights}




\section{Queries and Answers}

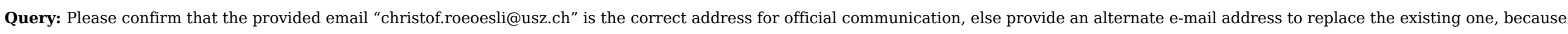
private e-mail addresses should not be used in articles as the address for communication.

Answer: The email address is correct.

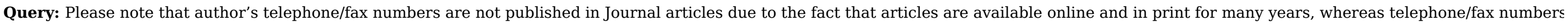
are changeable and therefore not reliable in the long term.

Answer: That is fine.

Query: Highlights should only consist of "125" characters per bullet point, including spaces. The highlights provided are too long; please edit them to meet the requirement.

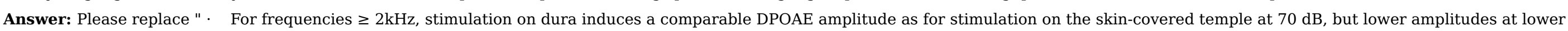
levels."

by

". At $70 \mathrm{~dB}$, stimulation on dura and on the skin-covered temple induce a comparable DPOAE amplitude $\geq 2 \mathrm{kHz}$.

- Below $70 \mathrm{~dB}$, stimulation on dura induces lower amplitudes compared to stimulation on the skin-covered mastoid $\geq 2 \mathrm{kHz}$."

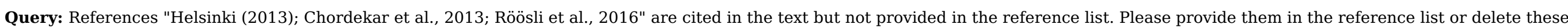
citations from the text.

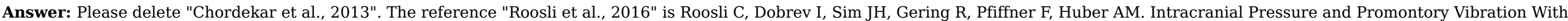
Soft Tissue Stimulation in Cadaveric Human Whole Heads. Otol Neurotol. 2016 Oct;37(9):e384-90. doi: 10.1097/MAO.0000000000001121."

The Reference "Helsinki (2013) is cited as

"World Medical Association. World Medical Association Declaration of Helsinki: ethical principles for medical research involving human subjects. JAMA. 2013;310(20):2191-4.

doi:10.1001/jama.2013.281053".

Query: The citation "Michel, 1992" has been changed to match the author name in the reference list. Please check here and in subsequent occurrences.

Answer: That's fine.

Query: Please check the date of the ref. Mattingly et al., 2015.

Answer: Correct.

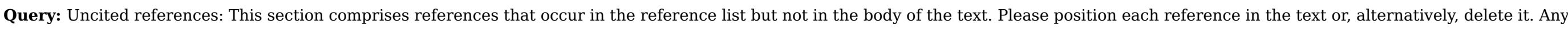
reference not dealt with will be retained in this section. Thank you.

Answer: The reference corresponds to "Helsinki, 2013".

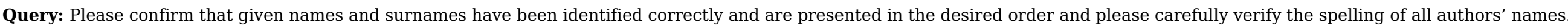


Answer: Correct

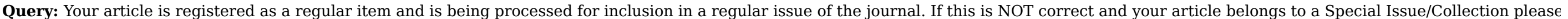
contact n.bhaskaran@elsevier.com immediately prior to returning your corrections.

Answer: That's correct. 